\title{
Modification of sandy soil hydrophysical environment through bagasse additive under laboratory experiment
}

\author{
A.A. Abd El-Halim ${ }^{*}$ and Arunsiri Kumlung ${ }^{2}$ \\ ${ }^{1}$ Department of Soil and Water, Tanta University, 31527 Tanta, Egypt \\ ${ }^{2}$ Department of Soil Science, Kasetsart University, Kasetsart, Thailand
}

Received June 15, 2014; accepted December 2, 2014

\begin{abstract}
A b s t r a c t. Until now sandy soils can be considered as one roup having common hydrophysical problems. Therefore, a laboratory experiment was conducted to evaluate the influence of bagasse as an amendment to improve hydrophysical properties of sandy soil, through the determination of bulk density, aggregatesize distribution, total porosity, hydraulic conductivity, pore-space structure and water retention. To fulfil this objective, sandy soils were amended with bagasse at the rate of $0,0.5,1,2,3$ and $4 \%$ on the dry weight basis. The study results demonstrated that the addition of bagasse to sandy soils in between 3 to $4 \%$ on the dry weight basis led to a significant decrease in bulk density, hydraulic conductivity, and rapid-drainable pores, and increase in the total porosity, water-holding pores, fine capillary pores, water retained at field capacity, wilting point, and soil available water as compared with the control treatment.

K e y w o r d s: sugarcane straw, sandy soil, physical properties, hydraulic properties
\end{abstract}

\section{INTRODUCTION}

The success or failure of agricultural projects and arable farming often hinges on the physical properties of the soil, because they are more difficult to change than the chemical properties (Chude et al., 2011).

Sandy soils are a practically important economic resource for agricultural production in many parts of the world. Although sandy soils differ in their origin, formation and properties, yet they can be considered as one group having common problems (Bruand et al., 2005; Shepherd et al., 2002; Wanas and Omran, 2006). The problems that we are facing here are the hydrophysical properties, such as loss of structure which associated with low total porosity, rapid hydraulic conductivity and low water retention.

Bagasse is the fibrous residue of corn stalk that is obtained after the extraction of sugarcane juice by the milling process. The ready availability of bagasse, as a byproduct of sugar production, has always made it an attractive fuel for the sugar industry, and covers the energy requirements (electricity/steam) of the industry. Thus, it has been used as fuel in the boilers of the sugar factories since the beginning of the 20th century. These wastes need better utilisation instead of combustion. One of the promising approaches to use bagasse waste is as a low-cost soil amendment.

As reported in previous literature, the use of various organic soil amendments is receiving increased interest, especially to improve the hydrophysical properties of sandy soils (Essien, 2011; Liang et al., 2011; Mosesl et al., 2013; Tangkoonboribun et al., 2006; Wang et al., 2014). In spite of that, many of those studies have highlighted the potential benefits of applying these wastes to soils and also the need for supplementary fertilizer to ensure optimum growth.

Applying bagasse to sandy soils may be a good way to help solving the hydrophysical problems of sandy soils, but limited research has been done to quantify the beneficial effect of applying bagasse to sandy soils. Therefore, this work was conducted to evaluate its effects in different percentages on the hydrophysical characteristics of sandy soils experimentally, under laboratory environment. 


\section{MATERIALS AND METHODS}

The soil sample used was well-graded sands collected from Phrathan Dongrang, Amphoe Tha Maka, Kanchanaburi Province, Thailand, classified as Suk Fine-loamy, siliceous, subactive, isohyperthermic Typic Paleustults (Udomsri et al., 2004). The soil was air-dried and then passed through a 2-mm sieve before usage.

The bagasse residue used as an additive in the experimental procedure was obtained locally from the centre of Sugar and Sugarcane, Kasetsart University, Kamphaeng Sean campus, Nakom Pathom Province of Thailand, gently crushed and passed through a 2-mm sieve and stored in airtight containers to avoid pre-hydration until usage.

One thousand and five hundred grams of sandy soil was carefully amended by bagasse. The soil was amended by the addition of $0.5,1,2,3$ and $4 \%$ bagasse on the dry weight basis to prepare five bagasse-amended soil treatments, in addition to $0 \%$ of bagasse (non-amended soil or control treatment). All mixing was done manually and proper care was taken to prepare homogeneous mixtures at each stage.

The non-amended soil and bagasse-amended soil treatments were placed in square plastic pots $(30 \mathrm{~cm}$ length $\times$ $30 \mathrm{~cm}$ width $\times 20 \mathrm{~cm}$ height) and then incubated at air temperature of $29 \pm 2^{\circ} \mathrm{C}$ for two months. During incubation soil water content was adjusted every four days to maintain it at the equivalent to $60 \%$ of water holding capacity based on weight. All treatments were replicated four times. After two months of incubation, undisturbed core samples $(5.5 \mathrm{~cm}$ height $\times 5 \mathrm{~cm}$ diameter) were taken from each treatment for further analysis.

Bulk density $(\mathrm{Bd})$ determination was performed as described in (Estefan et al., 2013).

Total soil porosity was calculated assuming particle density $2.65 \mathrm{~g} \mathrm{~cm}^{-3}$ using the following equation (Bhogal et al., 2009):

Total soil porosity $=[1$ - (bulk density/2.65) $]$ 100\%.

The aggregate size distribution of each treatment was determined using the same core samples that were used to calculate the bulk density. One hundred grams of the oven dried sample was used to calculate the aggregate size distribution by dry sieving method. The sample was sieved for $10 \mathrm{~min}$ through a number of sieves with sizes of 2,1 , $0.5,0.25,0.075 \mathrm{~mm}$ and the pan. The percentage of soil passing through each sieve was calculated, and then mean weight diameter $(M W D)$ was computed from the following equation:

$$
M W D=\sum_{i=1}^{n} \bar{X}_{i} w_{i}
$$

where: $M W D$ is the mean weight diameter $(\mathrm{mm}), \bar{X}$ is the mean diameter of each size fraction $(\mathrm{mm}), w_{i}$ is the proportion of the total sample weight in the corresponding size fraction, and $\mathrm{n}$ is the number of size fractions.
The constant-head permeability tests were conducted to obtain saturated hydraulic conductivity $\left(K_{s}\right)$ values. These tests were performed as follows: undisturbed core samples were covered at one end with a piece of Muslin cloth held in place with the aid of rubber bands and allowed to stand overnight in water to ensure complete saturation. The inflow of fluid was maintained at a constant head above a datum. The time taken to fill a volume of $250 \mathrm{ml}$ using the graduated cylinder was measured. This process was repeated four times and the average time was computed. Using Darcy law, the saturated hydraulic conductivity was determined using the following equation:

$$
K_{s}=Q L / h A t
$$

where: $K_{s}$ is the saturated hydraulic conductivity $\left(\mathrm{cm} \mathrm{s}^{-1}\right)$, $L$ is the length of the sample $(\mathrm{cm}), A$ is the cross-sectional area of the sample $\left(\mathrm{cm}^{2}\right), Q$ is the average outflow rate $\left(\mathrm{cm}^{3} \mathrm{~s}^{-1}\right), h$ is the fluid head difference across the sample, $(\mathrm{cm})$, and $t$ is the average time (s).

The non-amended or bagasse-amended undisturbed soil core samples (duplicate) were saturated for $24 \mathrm{~h}$, and then the saturation water content (SWC) was determined. The pressure plate apparatus (Soil Moisture Equipment Corp., Santa Barbara, CA, USA) was used to quantify the moisture retained at 0.1, 0.33 and 15 bar tensions (Estefan et al., 2013). The gravimetric water content at each pressure level was calculated. Then, field water-holding capacity (FC) and wilting point (WP) were determined at 0.1 bar and 15 bar pressures, respectively. Plant-available watercontent (AWC) was calculated from the difference between the moisture contents of water-holding capacity and wilting point.

Pore size distribution was determined according to the equation:

$$
P=(2 \sigma \cos \theta) / r
$$

where: $r$ is pore radius, $\sigma$ is the surface tension of water $\left(\sigma=0.072 \mathrm{~N} \mathrm{~m}^{-1}\right), \theta$ is the contact angle and $P$ is the applied pressure. When the contact angle equals zero, the pore diameters corresponding to pressure $0.1,0.33$ and 15 bars are equal to $28.8,8.6$ and $0.19 \mu \mathrm{m}$, respectively. Pores with diameter $>28.8 \mu \mathrm{m}$ were classified as rapid drainable pores (RDP) or 'macropores', pores with diameters of 28.8-0.19 $\mu \mathrm{m}$ as water holding pores (WHP), and pore with diameter $<0.19 \mu \mathrm{m}$ as fine capillary pores (FCP) or 'micropores' (Gonçalves et al., 2010).

The data were analyzed statistically using MSTATCTM version 2.0. Two-way ANOVA was used to determine the significant differences between means of all soil hydrophysical characteristics under different bagasse-amended soil treatments. The significant differences between the means were tested using Tukey honestly significant difference test at the $5 \%$ level. 


\section{RESULTS}

The effect of bagasse on soil-aggregate formation and mean weight diameter (MWD) for different treatments is shown in Table 1. The results showed that the 3 and $4 \%$ bagasse-amended soil treatments gave higher amounts of macroaggregates $(2-1,1-0.5$ and $0.5-0.25 \mathrm{~mm})$ compared to the non-amended soil treatment. On average, the macroaggregates obtained with the 3 and $4 \%$ bagasse-amended soil treatments increased by about 3.24 and $5.21 \%$ for the $2-1 \mathrm{~mm}$ aggregates, and by 2.54 and $3.95 \%$ for the 1-0.5 mm aggregates, respectively, compared to the nonamended soil treatment. The effect of bagasse on aggregate formation was also significant for the $0.5-0.25$ and 0.25 $0.075 \mathrm{~mm}$ aggregates. The 3 and $4 \%$ bagasse-amended soil treatments resulted in significantly lower amounts of $0.5-0.25 \mathrm{~mm}$ macroaggregates compared with the nonamended soil treatment. On average, the $0.5-0.25 \mathrm{~mm}$ aggregates obtained with the 3 and $4 \%$ bagasse-amended soil treatments decreased by 3.43 and $5.37 \%$, respectively, compared to the non-amended soil treatment. The 0.25 0.075 and $<0.075 \mathrm{~mm}$ microaggregates obtained with the 3 and 4\% SB-amended soil treatments were statistically lower than in the non-amended soil treatment. On average, the $0.25-0.075 \mathrm{~mm}$ microaggregates obtained with the 3 and $4 \%$ bagasse-amended soil treatments decreased by 2.16 and $3.36 \%$, respectively, compared to the non-amended soil treatment. Statistically, for different particle size classes, the aggregate-size distribution was apparently unaffected by the $0.5,1$ and $2 \%$ bagasse-amended soil treatments. The stabilisation of dry soil aggregation units may be evaluated by the mean weight diameter (MWD). If the MWD value is high, that indicates a predominance of larger aggregates. The MWD increased with the 3 and $4 \%$ bagasse-amended soil treatments (Table 1). There was a significant statistical difference between the MWD of the non-amended soil treatment and the 3 and $4 \%$ bagasse-amended soil treat- ments: they increased the MWD by about 5.8, and $12.9 \%$, respectively. The larger MWD values for the soils exhibit a further significant improvement in the larger aggregates with the addition of bagasse. However, the $0.5,1$ and $2 \%$ bagasse-amended soil treatments had no significant effect on the aggregate formation.

The bulk density $(\mathrm{Bd})$ of the soil remained almost unchanged after mixing with the SB. except for the highest concentrations of 3 and $4 \%$ when it decreased by 34.4 , and $47.3 \%$, respectively, compared with the non-amended soil treatment (Table 2). The degree to which the total porosity values increased with the SB additions varied among the bagasse-amended soil treatments (Table 2). The total porosity percentage of the non-amended soil treatment was $43.33 \%$, therefore the increase in porosity percentage compared to the non-amended soil treatment was $1.19,3.59$ and $5.59 \%$ for the $0.5,1$ and $2 \%$ bagasse-amended soil treatments, respectively, while the 3 and $4 \%$ SB-amended soil treatments leap-jumped to 19.47 and $26.78 \%$, respectively. It is clear that the bagasse used exhibited beneficial effects towards modifying the pore size distribution pattern (Table 2). The addition of bagasse significantly $(p<0.0001)$ altered the rapid drainable pores (RDP), the water holding pores (WHP), and the fine capillary pores (FCP). The addition of bagasse to the soil was effective to decrease RDP (which is responsible for the rapid water loss under gravity force) and increase WHP and FCP (which are responsible for retaining water against gravity force). For the RDP, the maximum reduction observed with the 4 and $3 \%$ bagasse-amended soil treatments was 27.09 and $25.85 \%$, respectively. On the other hand, for the FCP, the maximum increase was 4.97 and 3.95 times with the 4 and 3\% bagasse-amended soil treatments, compared with the nonamended soil treatment, respectively. The ratio between micro and macropores is of great importance for identifying the rate of water retention and water movement in

T a b l e 1. Aggregate size composition and mean weight diameter (MWD) for different percentages of bagasse added to the soil

\begin{tabular}{ccccccc}
\hline & \multicolumn{5}{c}{ Sieve diameter $(\mathrm{mm})$} & \multirow{2}{*}{$\begin{array}{c}\text { MWD } \\
(\mathrm{mm})\end{array}$} \\
\cline { 2 - 6 } Bagasse (\%) & $2-1$ & $1-0.5$ & $0.5-0.25$ & $0.25-0.075$ & $<0.075$ & \\
\cline { 2 - 5 } & \multicolumn{5}{c}{ Aggregates size composition (\%) } \\
\hline \multirow{2}{*}{0.0} & $11.76 \pm 0.48 \mathrm{~b}$ & $33.02 \pm 0.69 \mathrm{~b}$ & $41.22 \pm 0.51 \mathrm{a}$ & $13.75 \pm 0.65 \mathrm{ab}$ & $0.25 \pm 0.02 \mathrm{a}$ & $0.62 \pm 0.01 \mathrm{c}$ \\
0.5 & $12.42 \pm 0.46 \mathrm{~b}$ & $33.26 \pm 0.64 \mathrm{~b}$ & $39.53 \pm 0.49 \mathrm{ab}$ & $14.66 \pm 0.61 \mathrm{a}$ & $0.12 \pm 0.01 \mathrm{bc}$ & $0.63 \pm 0.01 \mathrm{c}$ \\
1.0 & $11.97 \pm 0.36 \mathrm{~b}$ & $33.50 \pm 0.26 \mathrm{~b}$ & $40.67 \pm 0.25 \mathrm{ab}$ & $13.60 \pm 0.27 \mathrm{ab}$ & $0.26 \pm 0.03 \mathrm{a}$ & $0.63 \pm 0.01 \mathrm{c}$ \\
2.0 & $11.96 \pm 0.30 \mathrm{~b}$ & $33.47 \pm 0.43 \mathrm{~b}$ & $40.47 \pm 0.24 \mathrm{ab}$ & $13.91 \pm 0.56 \mathrm{ab}$ & $0.19 \pm 0.02 \mathrm{ab}$ & $0.63 \pm 0.01 \mathrm{c}$ \\
3.0 & $15.00 \pm 0.28 \mathrm{a}$ & $35.56 \pm 0.45 \mathrm{ab}$ & $37.79 \pm 0.26 \mathrm{bc}$ & $11.59 \pm 0.47 \mathrm{bc}$ & $0.06 \pm 0.01 \mathrm{c}$ & $0.67 \pm 0.01 \mathrm{~b}$ \\
4.0 & $16.97 \pm 0.60 \mathrm{a}$ & $36.97 \pm 0.44 \mathrm{a}$ & $35.85 \pm 0.54 \mathrm{c}$ & $10.15 \pm 0.40 \mathrm{c}$ & $0.07 \pm 0.01 \mathrm{c}$ & $0.70 \pm 0.01 \mathrm{a}$ \\
\hline
\end{tabular}

Distinct letters in the column indicate significant differences according to Tukey test $(\mathrm{p} \leq 0.0001)$. 
T a b l e 2. Bulk density (Bd), total porosity, rapid drainable pores (RDP), water holding pores (WHP), fine capillary pores (FCP) and micro/macropores ratio for different percentages of bagasse added to the soil

\begin{tabular}{|c|c|c|c|c|c|c|}
\hline \multirow{4}{*}{ Bagasse $(\%)$} & \multirow{4}{*}{$\begin{array}{c}\mathrm{Bd} \\
\left(\mathrm{g} \mathrm{cm}^{-3}\right)\end{array}$} & \multirow{4}{*}{$\begin{array}{c}\text { Total } \\
\text { porosity } \\
(\%)\end{array}$} & \multicolumn{3}{|c|}{ Pore-size distribution (\%) } & \multirow{4}{*}{$\begin{array}{c}\text { Micro/ } \\
\text { macropores } \\
\text { ratio }\end{array}$} \\
\hline & & & \multirow{2}{*}{$\begin{array}{c}\begin{array}{c}\text { Macropores } \\
(>28.8 \mu \mathrm{m})\end{array} \\
\text { RDP }\end{array}$} & \multicolumn{2}{|c|}{ Micropores $(<28.8 \mu \mathrm{m})$} & \\
\hline & & & & WHP & FCP & \\
\hline & & & $>28.8 \mu \mathrm{m}$ & $28.8-0.19 \mu \mathrm{m}$ & $<0.19 \mu \mathrm{m}$ & \\
\hline 0.0 & $1.50 \pm 0.01 \mathrm{a}$ & $43.33 \pm 0.13 \mathrm{~d}$ & $90.63 \pm 0.44 a$ & $4.39 \pm 0.82 b$ & $4.98 \pm 0.03 \mathrm{c}$ & $0.10 \pm 0.01 b$ \\
\hline 0.5 & $1.47 \pm 0.01 \mathrm{ab}$ & $44.52 \pm 0.29 \mathrm{~d}$ & $90.31 \pm 0.72 \mathrm{a}$ & $2.98 \pm 1.59 \mathrm{~b}$ & $6.71 \pm 0.20 \mathrm{c}$ & $0.11 \pm 0.02 b$ \\
\hline 1.0 & $1.40 \pm 0.01 \mathrm{bc}$ & $46.92 \pm 0.23 c$ & $87.66 \pm 0.07 \mathrm{ab}$ & $1.25 \pm 0.10 \mathrm{~b}$ & $11.09 \pm 0.01 \mathrm{~b}$ & $0.14 \pm 0.01 b$ \\
\hline 2.0 & $1.35 \pm 0.01 \mathrm{c}$ & $48.92 \pm 0.19 \mathrm{c}$ & $84.71 \pm 0.04 b$ & $4.47 \pm 1.03 \mathrm{~b}$ & $10.82 \pm 0.44 b$ & $0.18 \pm 0.02 b$ \\
\hline 3.0 & $0.98 \pm 0.03 \mathrm{~d}$ & $62.80 \pm 1.01 \mathrm{~b}$ & $64.78 \pm 1.05 \mathrm{c}$ & $15.56 \pm 2.26 \mathrm{a}$ & $19.66 \pm 0.27 \mathrm{a}$ & $0.54 \pm 0.04 \mathrm{a}$ \\
\hline 4.0 & $0.79 \pm 0.01 \mathrm{e}$ & $70.11 \pm 0.25 \mathrm{a}$ & $63.54 \pm 0.81 \mathrm{c}$ & $16.67 \pm 0.68 \mathrm{a}$ & $19.79 \pm 1.18 \mathrm{a}$ & $0.57 \pm 0.03 \mathrm{a}$ \\
\hline
\end{tabular}

Explanations as in Table 1.

T a b l e 3. Saturated hydraulic conductivity $\left(K_{s}\right)$, saturation water content (SWC), field water-holding capacity (WHC), wilting point (WP), and plant-available water content (AWC) for different percentages of bagasse added to the soil

\begin{tabular}{cccccc}
\hline & $K_{s}$ & SWC & WHC & WP & AWC \\
\cline { 3 - 6 }$\left(\mathrm{cm} \mathrm{h}^{-1}\right)$ & $4.21 \pm 0.01 \mathrm{a}$ & $40.94 \pm 1.07 \mathrm{c}$ & $3.85 \pm 0.28 \mathrm{c}$ & $2.04 \pm 0.04 \mathrm{~d}$ & $1.81 \pm 0.24 \mathrm{~b}$ \\
\hline 0.0 & $4.17 \pm 0.01 \mathrm{~b}$ & $45.27 \pm 1.37 \mathrm{bc}$ & $4.41 \pm 0.46 \mathrm{c}$ & $3.03 \pm 0.01 \mathrm{c}$ & $1.37 \pm 0.45 \mathrm{~b}$ \\
0.5 & $4.11 \pm 0.01 \mathrm{c}$ & $47.69 \pm 0.71 \mathrm{~b}$ & $5.89 \pm 0.06 \mathrm{bc}$ & $5.30 \pm 0.08 \mathrm{~b}$ & $0.59 \pm 0.03 \mathrm{~b}$ \\
1.0 & $4.10 \pm 0.01 \mathrm{c}$ & $48.56 \pm 0.62 \mathrm{~b}$ & $7.41 \pm 0.41 \mathrm{bc}$ & $5.22 \pm 0.13 \mathrm{~b}$ & $2.19 \pm 0.28 \mathrm{~b}$ \\
2.0 & $4.01 \pm 0.01 \mathrm{c}$ & $62.32 \pm 0.68 \mathrm{a}$ & $21.96 \pm 0.89 \mathrm{a}$ & $12.15 \pm 0.06 \mathrm{a}$ & $9.81 \pm 0.83 \mathrm{a}$ \\
3.0 & $4.01 \pm 0.01 \mathrm{~d}$ & $63.44 \pm 1.35 \mathrm{a}$ & $23.11 \pm 0.02 \mathrm{a}$ & $12.34 \pm 0.03 \mathrm{a}$ & $10.76 \pm 0.01 \mathrm{a}$ \\
\hline
\end{tabular}

Explanations as in Table 1.

the soil. The bagasse-amended soil treatments were more effective on the micro/macropore ratio than non-amended soil treatment (Table 2). It is interesting to note that mixing bagasse residue with sandy soil beneficially modified this ratio. However, micro/macroporosity in the untreated soil was $0.10: 1$; it increased due to soil conditioning to 0.11 , $0.14,0.18,0.54$ and $0.57: 1$ at the addition of bagasse at the rates of $0.5,1,2,3$ and $4 \%$, respectively. However, statistically the micro/macropore ratio was apparently unaffected by the $0.5,1$ and $2 \%$ bagasse-amended soil treatments. Also, there were no statistical differences between the 3 and $4 \%$ bagasse-amended soil treatments.

The effect of the addition of bagasse in different percentages to the sandy soils on the saturated water content (SWC), field water-holding capacity (WHC), permanent- wilting point (WP), and available water content (AWC) were significantly different (Table 3 ). The 3 and $4 \%$ bagasseamended soil treatments exhibited significant increases in the SWC, WHC, WP, and AW $(\mathrm{p}<0.0001)$. The amount of available water retained by the 3 and $4 \%$ bagasseamended soil treatments was greater than that retained by non-amended soil treatment by 8 and $9 \%$, respectively. In addition, the 3 and $4 \%$ bagasse-amended soil treatments led to an increase in the WHC by 18 and $19 \%$, respectively, compared to the non-amended soil treatment. However, no effect was detected in the $0.5,1$ and $2 \%$ bagasse-amended soil treatments on the SWC, WHC, WP, and AW. It is clear that the addition of bagasse to sandy soils led to a slight decrease in the saturated hydraulic conductivity $\left(K_{s}\right)$ (Table 3 ). It is worth noting that the 3 and $4 \%$ bagasse-amended soil 
treatments exhibited the highest reduction values for the $K_{s}$, amounting to $4.75 \%$ of the two treatments. On the other side, the statistical analysis indicates no significant differences between the three other treatments.

\section{DISCUSSION}

There was a significant increase in the formation of larger aggregates observed in the soil treatments with 3 and $4 \%$ bagasse, and that indicates an increase in the interparticle bond strength, which could be due to enhanced inter-particular aggregate cohesion due to inward diffusion of binding organic substances within the aggregates. In the same trend, an 'addition of materials rich in organic carbon leads to an improvement of the aggregation status of the soil' (Aggelides and Londra, 2000; Bandyopadhyay et al., 2010; Dexter et al., 2008; Ferreras et al., 2006; Tangkoonboribun et al., 2006). This is likely reflected in the formation of larger macroaggregates in the bagasse-amended soil treatments by the coalescence of microaggregates, where a significant reduction in microaggregates was observed, which resulted in an increase of the MWD and a decrease of the bulk density. Because of the decreased bulk density, the pore-size distribution was altered and the relative number of small pores or micropores (ie WHP and FCP) increased compared to the non-amended soil treatment. The increase of micropores can be explained by the change of phase composition of the soil matrix due to sugarcane bagasse addition, where the addition of sugarcane bagasse reduced the solid phase and increased the air phase compared to the non-amended soil treatment. This reduction of solid phase may increase inter- and intra-aggregate spaces which are responsible for the increase of FCP and WHP. Therefore, there was a pronounced effect on the moisture content at saturation point, field capacity, wilting point and, consequently, available water. In other words, sugarcane bagasse applied at the rate of 3 and $4 \%$ greatly improved pore size distribution of treated soils towards a high moisture retention increase and lower loss of water from the soil by leaching or deep percolation, as could be indicated by the increase of micro/ macropores ratio. In that connection, 'applied compost plant residue conditioners had a positive effect on hydrophysical properties of sandy soil, ie decreasing soil bulk density as well as macroporosity (drainage pores) at the expense of ones. Also, increasing water holding pores, and thus, increasing the moisture content at field capacity compared with moisture at wilting point. In addition, decreasing the mean diameter of soil pores and turns its water transmitting pro-perties namely hydraulic conductivity' (Ali, 2011; El-Hady and Abo-Sedera, 2006; Wanas and Omran, 2006). Strictly speaking, the results proved that sugarcane bagasse caused a reduction of macropores (RDP) and an increase of micropores (WHP and FCP), which should be reflected in the hydraulic conductivity reduction. In the same line, 'in an experiment on the sandy loam soil, there was a sig- nificant interaction between the aggregate size and the organic matter content (sugarcane bagasse) in their effect on reducing saturated hydraulic conductivity' (Lado et al., 2004). On the other hand, sugarcane bagasse applied at the rate of $0.5,1$ and $2 \%$ did not show any considerable reduction in bulk density, macropores, and water holding pores. However, it showed a corresponding increase in the total porosity, indicating that small additions of bagasse may be insufficient for improving such properties when mixed with the sandy soil. Finally, the study suggested that sugarcane bagasse significantly led to an improvement in the hydrophysical properties of sandy soils, especially when added at the rate of $3 \%$ on the soil dry weight basis, and above this percentage the improvement was much less significant.

\section{CONCLUSIONS}

1. Significant changes in soil bulk density, total porosity, aggregate formation, water retention, pore-size distribution, and hydraulic conductivity were observed after addition of sugarcane bagasse at the rate of 3 to $4 \%$ to sandy soil.

2. Sugarcane bagasse enhanced the formation of the larger macroaggregates $(2-1 \mathrm{~mm})$ and decreased the amount of $<0.075 \mathrm{~mm}$ microaggregates, thus decreasing the bulk density and saturated hydraulic conductivity.

3. Application of bagasse significantly increased total porosity. The degree to which the total porosity values increased with the bagasse addition and pore-size distribution varied among the different bagasse treatments - it decreased the volume of the rapid drainable pores and increased that of both the water holding and the fine capillary pores.

4. Application of bagasse significantly increased the soil water retention at its water-holding capacity, wilting point, and increased plant available water content.

5. The study suggested that sugarcane bagasse significantly led to an improvement in the hydrophysical properties of sandy soils, especially when added at rates between 3 to $4 \%$ on the soil dry weight basis.

\section{REFERENCES}

Aggelides S.M. and Londra PA., 2000. Effects of compost produced from town wastes and sewage sludge on the physical properties of a loamy and a clay soil. Bioresour Technol., 71, 253-259.

Ali L.K.M., 2011. Significance of applied cellulose polymer and organic manure for ameliorating hydro-physico-chemical properties of sandy soil and maize yield. Aust. J. Basic. Appl. Sci., 5(6), 23-35.

Bandyopadhyay K.K., Misra A.K., Ghosh P.K., and Hati K.M., 2010. Effect of integrated use of farm-yard manure and chemical fertilizeres on soil physical properties and productivity of soybean. Soil Till. Res., 110, 115-125.

Bhogal A., Nicholson F.A., and Chambers B.J., 2009. Organic carbon additions: effects on soil bio-physical and physicochemical properties. Eur. J. Soil Sci., 60, 276-286. 
Bruand A., Hartmann C., and Lesturgez G., 2005. Physical properties of tropical sandy soils: A large range of behaviors. Proc. Symp. Int. Management of Tropical Sandy Soils for Sustainable Agriculture: A Holistic Approach for Sustainable Development of Problem Soils in the Tropics. November 27 - December 2, Khon Kaen, Thailand.

Chude V.O., Malgwi W.B., Amapu I.Y., and Ano O.A., 2011. Manual on Soil Fertility Assessment. Federal Fertilizer Department (FFD) in collaboration with National Programme for Food Security, Abuja, Nigeria.

Dexter A.R., Richard G., Arrouays D., Czyż E.A., Jolivet C., and Duval O., 2008. Complexed organic matter controls soil physical properties. Geoderma, 144, 620-627.

El-Hady O.A. and Abo-Sedera S.A., 2006. Conditioning effect of composts and acrylamide hydrogels on a sandy calcareous soil. II- Physico-bio-chemical properties of the soil. Int. J. Agric. Biol., 8(6), 876-884.

Essien O.E., 2011. Effect of varying rates of organic amendments on porosity and infiltration rate of sandy loam soil. J. Agric. Environ., 12, 51-58.

Estefan G., Sommer R., and Ryan J., 2013. Methods of soil, plant, and water analysis: A manual for the west, Asia and North Africa region. ICARDA, Beirut, Lebanon.

Ferreras L., Gomez E., Toresani S., Firpo I., and Rotondo R., 2006. Effect of organic amendments on some physical, chemical and biological properties in a horticultural soil. Bioresource Technol., 97, 635-640.

Gonçalves R.A.B., Gloaguen T.V., Folegatti M.V., Libardi P.L., Lucas Y., and Montes C.R., 2010. Pore size distribution in soils irrigated with sodic water and wastewater. R. Bras. Ci. Solo., 34, 701-707.
Lado M., Paz A., and Ben-Hur M., 2004. Organic matter and aggregate-size interactions in saturated hydraulic conductivity. Soil Sci. Soc. Am. J., 68, 234-242.

Liang W., Wu X., Zhang S., Xing Y., and Wang R., 2011. Effect of organic amendments on soil water storage in the Aeolian sandy land of northeast China. Int. Conf. Electrical and Control Engineering, September 16-18, Yichang, China.

Mosesl G., Oriola F.O.P., and Afolayan J.O., 2013. The impact of compactive effort on the long term hydraulic conductivity of compacted foundry sand treated with bagasse ash and permeated with municipal solid waste landfill leachate. Front. Geotech. Eng., 2(1), 7-15.

Shepherd M.A., Harrison R., and Webb J., 2002. Managing soil organic matter - implications for soil structure on organic farms. Soil Use Manag., 18, 284-292.

Tangkoonboribun R., Rauysoongnern S., Rambo P.V., and Tumsan B., 2006. Effect of organic and clay material amendment on physical properties of degraded sandy soil for sugarcane production. Sugar Technol., 8(1), 44-48.

Udomsri S., Huntrakool K., and Watana S., 2004. Characterization of established soil series in the central plain region of Thailand. Office of Surveying and Mapping Technology, Department of Land Development, Kasetsart University, Kamphaeng Saen Campus Nakhon Pathom, Thailand.

Wanas Sh.A. and Omran W.M., 2006. Advantages of applying various compost types to different layers of sandy soil: 1Hydro-physical properties. J. Appl. Sci. Res., 2(12), 1298-130.

Wang L., Tong Z., Liu G., and Li Y., 2014. Characterization of biomass residues and their amendment effects on water sorption and nutrient leaching in sandy soil. Chemosphere, 107, 354-359. 